Original Article

Artigo Original

Clara Regina Brandão de Avila²

Keywords

Reading

Comprehension

Language

Education, Primary and Secondary Speech, Language, and Hearing Sciences

\author{
Descritores \\ Leitura \\ Compreensão \\ Linguagem \\ Ensino Fundamental e Médio \\ Fonoaudiologia
}

Correspondence address:

Eliane Mi Chang

Rua Botucatu, 802, Vila Clementino, São Paulo (SP), Brasil, CEP: 04023-062.

E-mail: changmi1004@gmail.com

Received: $12 / 02 / 2013$

Accepted: 05/15/2014

CoDAS 2014;26(4):276-85

\section{Reading comprehension on the last grades \\ of cicles I and II of elementary school}

\author{
Compreensão leitora nos últimos anos \\ dos ciclos I e II do ensino fundamental
}

\begin{abstract}
Purpose: To characterize students' performance in Cycle I and II of the Elementary School (EF), in decoding, reading comprehension and underlying skills of reading, and investigate correlations between these variables, in the absence and presence of reading comprehension deficits, identified by their teachers. Methods: 125 students from ES were grouped according to Cycle and presence or absence of reading comprehension impairments. Two Control (good readers from both Cycles) and two Research groups (poor readers from both Cycles) were established. Assessment involved: fluency and reading comprehension; oral comprehension; working and short-term phonological memory; grammar closure. It was compared (Mann-Whitney test): in intragroup study, both Control and Research groups; in intergroup study, Control and Research from different cycles, and Control I and Research II. Spearman coefficient investigated correlations. Results: Analyzing reading comprehension, we observed better performance of Control Groups in all tasks in comparison to the respective Research Groups, and better performance of Control II in comparison to Control I. Research Groups had similar results in most tests. Positive correlations have been observed between most of the variables. Conclusion: Students without reading comprehension impairments showed better performance in reading in both Cycles. Working memory and oral comprehension did not differentiate students with and without complaints in Cycle I, differently from what was observed in Cycle II. Research II presented similar or better performance than Research I and similar or worse performance than Control I. Underlying skills showed different profiles of correlation with reading comprehension capacity, according to the group.
\end{abstract}

\section{RESUMO}

Objetivo: Caracterizar o desempenho de escolares do Ciclo I e II do Ensino Fundamental (EF), em decodificação, compreensão leitora e habilidades subjacentes à leitura, e investigar correlações entre essas variáveis, na ausência e na presença de prejuízos da compreensão leitora, identificados pelos professores. Métodos: Participaram 125 escolares do EF, agrupados segundo o Ciclo e a presença ou ausência de indicativos de prejuízos de compreensão leitora. Estabeleceram-se dois Grupos Controle (bons compreendedores de ambos os Ciclos) e dois Grupos Pesquisa (pobres compreendedores de ambos os Ciclos). Avaliaram-se: fluência e compreensão leitora; compreensão oral; memória fonológica de curto prazo e operacional; closura gramatical. Comparou-se (Teste de Mann-Whitney): em estudo intragrupo, os dois Grupos Controle e os dois Grupos Pesquisa; em estudo intergrupo, Controle e Pesquisa dos diferentes ciclos e Controle I e Pesquisa II. O coeficiente de Spearman investigou correlações entre as variáveis. Resultados: Quanto à compreensão leitora, observou-se: melhor desempenho dos Controle em todas as tarefas, comparados aos respectivos Pesquisa; melhor desempenho do Controle II comparado ao Controle I. Os Pesquisa foram semelhantes na maioria das provas. Observaram-se correlações positivas entre a maioria das variáveis estudadas. Conclusão: Os Controle mostraram melhor desempenho em leitura, nos dois ciclos. Memória de trabalho e compreensão oral não diferenciaram escolares no Ciclo I, ao contrário do observado no Ciclo II. O Pesquisa II foi semelhante ou melhor que o Pesquisa I e semelhante ou pior que o Controle I. Habilidades subjacentes mostraram diferentes perfis de correlação com a capacidade de compreensão leitora, segundo o grupo.

Study carried out at the Department of Speech-Language Pathology and Audiology, Escola Paulista de Medicina, Universidade Federal de São Paulo - UNIFESP - São Paulo (SP), Brazil.

(1) Graduate Program in Sciences, Department of Speech-Language Pathology and Audiology, Escola Paulista de Medicina, Universidade Federal de São Paulo - UNIFESP - São Paulo (SP), Brazil.

(2) Department of Speech-Language Pathology and Audiology, Escola Paulista de Medicina, Universidade Federal de São Paulo - UNIFESP - São Paulo (SP), Brazil.

Financial support: Conselho Nacional de Desenvolvimento Científico e Tecnológico (CNPq).

Conflict of interests: nothing to declare. 


\section{INTRODUCTION}

The automatic and precise recognition of written words is primordial and indispensable to achieve reading comprehension. Alphabetic decoding, the first step toward automatic reading, is associated with reading comprehension performance, more so when the reader is close to initiating this learning process or the more functional deficits related to language or cognition he/she has ${ }^{(1-7)}$. When learning occurs without difficulties throughout schooling, it becomes evident that reading fluency is not the only ability underlying text comprehension. Being fluent is not sufficient, as demands that call for reasoning and inference elaboration become increasingly more essential for learning and evidence the strict relation between reading and oral comprehension $^{(8-20)}$. For this reason, one can think that different skills are demanded during the act of reading in each cycle of elementary school (ES). Indeed, as established by the National Curriculum Parameters (NCP) ${ }^{(19)}$, in the initial stages the learner's efforts are concentrated in mastering the alphabet to automatically recognize words. As schooling progresses, these efforts can and must be directed toward knowledge acquisition through the comprehension and apprehension of written content. Reading becomes essential for a good performance in school and also for sociocultural insertion ${ }^{(1,15,19)}$.

Despite the different conditions and demands of each ES cycle, children with adequate school performances will read in search of a meaning if they are instructed for that purpose from the beginning of the learning process ${ }^{(6,19)}$. Moreover, even the most proficient reader will be able to use decoding mechanisms to carry on reading when faced with an unknown word.

Clinical and educational studies have evidenced the large number of readers lacking in comprehension ${ }^{(6,9,11)}$. These difficulties are more frequently identified in the latter years of ES due to the cycle's demands. Probably, this percentage includes students who were instructed in this way and those who present real disorders that require effort, often unsuccessful, while reading ${ }^{(10)}$. Among reading comprehension deficits are certainly those that were developed since the early stages of literacy, with evident dysfunctions between decoding and comprehension, and those that are late effects of deficits in oral language development and of other subsystems besides the phonological, which is the most implicated system in decoding processes ${ }^{(1-18)}$.

To understand the reasons behind failures to comprehend and reflect about what was read, it is essential to identify which skills, specific to each school phase, are related to this difficulty. If different cognitive abilities are recruited to a greater extent in text comprehension in each stage of schooling, when assessed in different moments of ES they will show a specific set of functions and skills, impaired or not, that is proper to each cycle. This is one of the hypotheses in this study.

Some international studies show that readers with poor comprehension (poor comprehenders) can present reading levels similar to those of younger readers ${ }^{(1,3,10,14)}$. Longitudinal research has shown evidence of relation and association between the performances of students who are poor comprehenders on tasks that evaluate abilities underlying the process of learning how to read ${ }^{(1,21)}$. Although this is not a longitudinal study, we understood that identifying similarities and differences among reading performances of students at the end of each ES cycle could bring forth performance characteristics that are similar between poor comprehenders and younger typical readers. In this manner, it is possible to suggest assertive educational conducts or clinical intervention.

To research the differences and similarities of each phase of the process of learning how to read, with or without reading impairments, in this study our purpose was to characterize the performance of students in Cycles I and II of ES on tasks that evaluate from decoding to reading comprehension and the abilities that underlie each of these reading mechanisms, and to investigate the correlation between these variables in the presence or absence of reading comprehension impairments.

\section{METHODS}

This study was approved by the ethics committee of Universidade Federal de São Paulo, where the study was conducted (report number 195838) on February 08, 2013. It was initiated after we received the informed consent form signed by the parents or legal guardians, the term of assent from the participating students, and the term of consent from the participating schools. This research is part of a study in which, in addition to characterizing reading comprehension at the end of both ES cycles and investigating the relation between its underlying abilities, we aimed at identifying predictors of good comprehension in each stage of elementary schooling.

Teachers of the fourth and fifth, and eighth and ninth grades of three public ESs, located in the cities of São Paulo and Santo André, were asked to indicate two groups of students to participate in the study. Control group (CG): students with good reading comprehension and school performance, attested by marks above the average (considered satisfactory by the school) in the first school semester that preceded data collection; study group (SG): students considered as poor comprehenders, that is, with reading comprehension deficits, despite their evident ability to recognize written words.

The teachers were also instructed to abide by the following criteria to include students in the samples: absence of complaints related to or indicators of sensory (auditory and visual) and/or cognitive impairments and neurological or behavioral disorders. The following complementary inclusion criterion was also adopted: minimum accurate oral reading of 40 words per minute ${ }^{(21)}$. The participants were 125 students (49 boys, $39.20 \%$ ) enrolled in the fourth and fifth, and in the eighth and ninth grades of ES. They were grouped according to their school year (last years of Cycle I or Cycle II) and the presence (SG) or absence (CG) of indicators of difficulties with reading comprehension. The groups thus constituted were the following: CG I, composed of 42 students (13 boys) in the last grades of Cycle I (22 students enrolled in the fourth year and 20 in the fifth year) considered good readers, that is, with good reading comprehension and school performance (mean age of 9.7 years); CG II, composed of 41 students (21 boys) in the last grades of Cycle II (21 students enrolled in the eighth year and 20 in the ninth year) considered good readers, that is, with 
good reading comprehension and school performance (mean age of 13.6 years); SG I, composed of 20 students (13 boys) in the last grades of cycle I (10 students enrolled in the fourth year and 10 in the fifth year) indicated as having poor reading comprehension (mean age of 9.7 years); SG II, composed of 22 students (12 boys and 10 girls) in the last grades of cycle II of ES (11 students enrolled in the eighth year and 11 in the ninth year) indicated as having poor reading comprehension (mean age of 13.6 years).

It is worth highlighting that, in addition to being part of the public school system (one is a municipal school in São Paulo), the three schools are located in the same region (South in both cities), where socioeconomic levels, classified by the inhabitants' income, ranges between extremely low and low ${ }^{(22)}$.

\section{Procedures}

Data were collected individually, in rooms and at times determined by the school's board. The duration of each student's assessment varied between 20 and 40 minutes, and depended especially on reading fluency. Within this period, the participants were evaluated in three stages:

1. Evaluation of reading fluency parameters: calculation of the rate and accuracy of reading 38 words and 29 pseudowords orally, as isolated items; and calculation of the rate and accuracy of the oral reading of a text (initial procedure to meet the inclusion criteria) that was adequate to the individual's schooling ${ }^{(23)}$.

2. Evaluation of reading comprehension through answers given to open questions about the text ${ }^{(24)}$ (translated and adapted to Brazilian Portuguese) ${ }^{(25)}$, classified and grouped as follows: two questions of literal comprehension (LIT), related to explicit information; two inferential questions about textual cohesion (text-connecting, TC), which demanded the elaboration of inferences pertaining to implicit information, such as those concerning anaphoric relations; and two inferential questions to fill in gaps (gap-filling, GF), which required the integration of common knowledge and information contained in the narrative passage to reach comprehension. Two different protocols were used to assess reading comprehension: Protocol A, for students of up to 9 years of age, and protocol B, for students aged 10 and over. Three speech-language pathologists evaluated the answers; identified the correct ones; and attributed two points to correct answers, one to correct but incomplete answers, and zero to incorrect answers.

3. Evaluation of abilities that underlie reading comprehension: (a) oral comprehension, assessed through the analysis of the answers given to eight open questions concerning a story told orally and presented by the evaluator, titled "The monkey and the rabbit" (26). The same text was presented to all students, regardless of their school year. The questions were elaborated, classified, and chosen by two speech-language pathologists, based on the protocol of assessment of reading comprehension proposed by Cain and Oakhill ${ }^{(24)}$. Thus, the individuals' reading comprehension was assessed through four LIT, two TC, and two GF questions after they heard the story told by the same evaluator. The correct answers were computed in similar manner to the analysis of reading comprehension, and the total score was yielded by the sum of the points obtained in each question; (b) short-term phonological memory, analyzed through the sequential repetition of digits, a subtest (WISC III) ${ }^{(27,28)}$, and pseudowords of up to six syllables (PROHMELE) ${ }^{(11)}$, and working memory, assessed through the backward repetition of digits [Wechsler Intelligence Scale for Children (WISC) III] ${ }^{(27,28)}$; and (c) grammatical closure ${ }^{(29)}$, a task used to evaluate the students' ability to complete sentences using rules of gender, number, and verbal inflection correctly.

The answers given during the evaluation of working memory were analyzed as follows: (a) the score received corresponded to the number of syllables repeated correctly in each item, up to $50 \%$ of the longest length achieved; and (b) total number of correct answers. The subtest of digit repetition is composed of eight series of digits to be repeated in sequential order and seven to be repeated backwards. The quantity of digits increases gradually, and the application was suspended after two failed attempts on the same item.

The students' school performance was analyzed as follows: (a) the score received corresponded to the number of span digits repeated correctly, up to $50 \%$ of the longest length achieved; (b) number of correct answers in sequential and backward order, separately; and (c) weighted score, corrected by a psychologist. Concerning the task of grammatical closure, the sum of correct answers provided the raw score of each student.

\section{Statistical method}

Mann-Whitney's test was used to compare the study and control groups: CG I and SG I, CG II and SG II, CG I and CG II, SG I and SG II, and SG II and CG I. We also calculated the Z-scores, as the students' performances were evaluated through two different reading protocols. Spearman's correlation coefficient was used to correlate the variables investigated in the groups. In this study, we adopted a significance level of 5\% $(0.05)$ to treat the results statistically.

\section{RESULTS}

The mean values and standard deviations found during the assessment of each group show adequate parameters of reading fluency in both CGs (Table 1). However, the data pertaining to short-term phonological and working memory evidenced poor performances even in these two groups. Although there are no reference values described in the literature for the other variables, the CGs enabled the comparisons that characterized the performances in each group.

Upon comparing the groups based on the cycle (Table 2), CG I and CG II showed better performances in all variables of reading comprehension in relation to their respective SG. Moreover, concerning Cycle I, we observed that, with exception of the results found on the test of answering oral comprehension questions by GF and repetition of digits in the same 
Table 1. Summary measures of the variables reading of words and pseudowords, oral comprehension, short-term and working memory, grammatical closure, parameters of oral reading fluency, and reading comprehension (Z-scores)

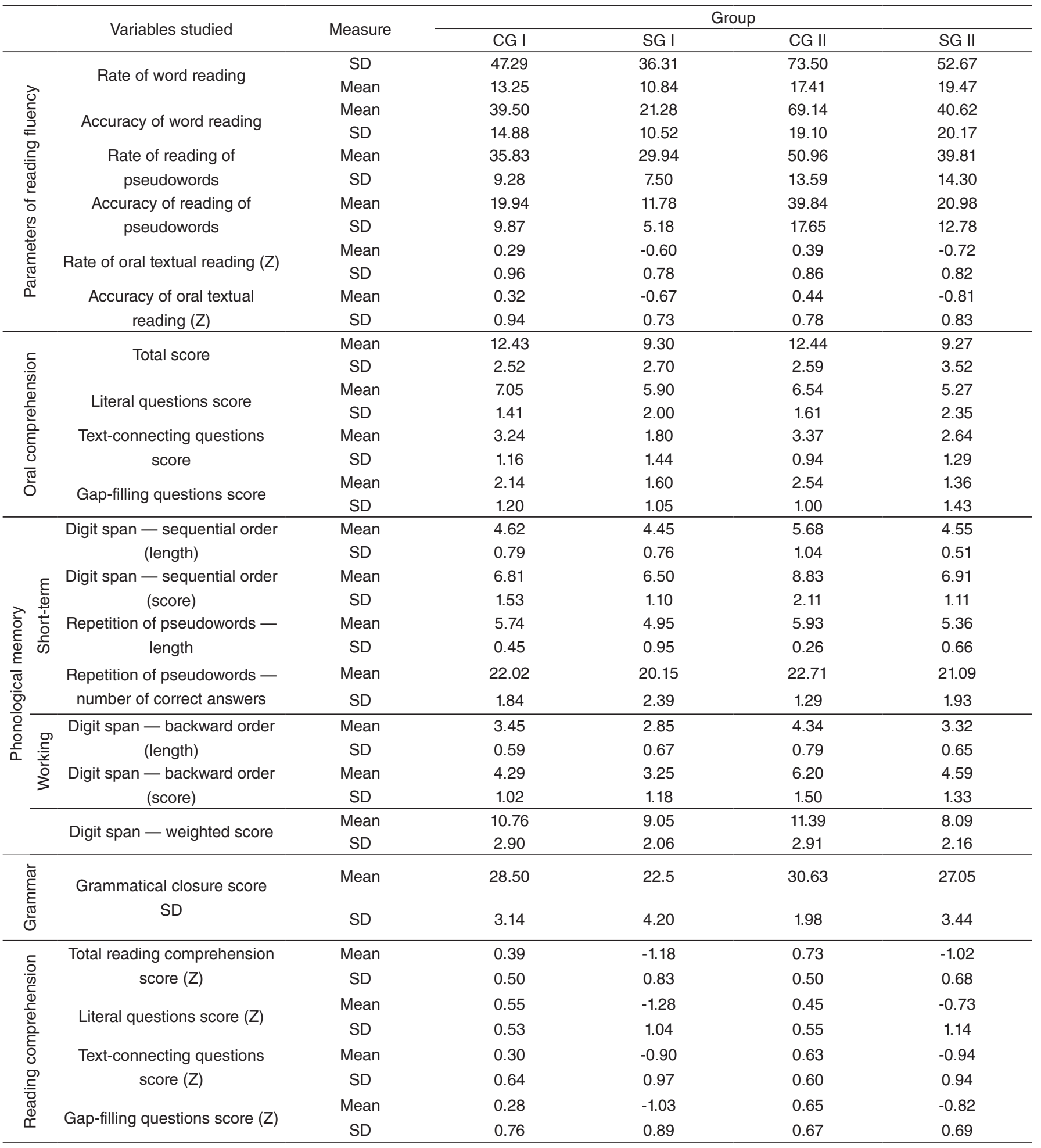

*Summary measures

Caption: CG I = control group in Cycle I; SG I = study group in Cycle I; CG II = control group in Cycle II; SG I = study group in Cycle II; SD = standard deviation; Z = Z-score

order, SG I presented worse performances than CG I in all other variables evaluated. The comparison based on Cycle II showed poor performances of SG II in relation to CG II in all variables studied.
When the cycles were compared by group (Table 3 ), we observed overall better performances in CG II in relation to CG I in regard to reading comprehension, with exception of the test of answering LIT questions, in which both CGs presented similar performances. 
Table 2. Intergroup comparisons in each cycle

\begin{tabular}{|c|c|c|c|c|c|c|c|c|c|}
\hline & \multirow{2}{*}{ Variable studied } & \multicolumn{4}{|c|}{ CG I x SG I } & \multicolumn{4}{|c|}{ CG \|x SG ॥ } \\
\hline & & Mann-Whitney U & Z & $\mathrm{p}$-value & Result & Mann-Whitney U & z & $p$-value & Result \\
\hline \multirow{6}{*}{ 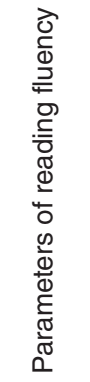 } & Words: rate & 228.00 & -2.893 & $0.004^{*}$ & CG I>SG I & 173.00 & -4.012 & $0.000^{*}$ & CG $\|>S G\|$ \\
\hline & Words: accuracy & 138.50 & -4.239 & $0.000^{*}$ & CG I>SG I & 131.00 & -4.615 & $0.000^{*}$ & CG $\|>S G\|$ \\
\hline & Pseudowords: rate & 272.00 & -2.229 & $0.026^{\star *}$ & CG I>SG I & 244.00 & -2.987 & $0.003^{*}$ & $C G\|>S G\|$ \\
\hline & Pseudowords: accuracy & 202.00 & -3.196 & $0.001^{*}$ & CG I>SG I & 139.50 & -4.491 & $0.000^{*}$ & CG $\|>S G\|$ \\
\hline & Text: rate (Z-score) & 186.00 & -3.442 & $0.001^{*}$ & CG I>SG I & 156.00 & -4.254 & $0.000^{*}$ & $C G\|>S G\|$ \\
\hline & Text: accuracy (Z-score) & 167.00 & -3.734 & $0.000^{*}$ & CG I>SG I & 126.000 & -4.686 & $0.000^{*}$ & CG $\|>S G\|$ \\
\hline \multirow{4}{*}{ 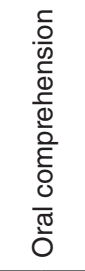 } & Total score & 167.00 & -3.890 & $0.000^{*}$ & CG I>SG I & 219.00 & -3.400 & $0.001^{*}$ & CG $\|>S G\|$ \\
\hline & Literal questions & 278.50 & -2.360 & $0.018^{\star *}$ & CG I>SG I & 313.50 & -2.100 & $0.036^{\star *}$ & $C G\|>S G\|$ \\
\hline & Text-connecting questions & 198.00 & -3.701 & $0.000^{*}$ & CG I>SG I & 314.50 & -2.284 & $0.022^{* *}$ & CG $\|>S G\|$ \\
\hline & Gap-filling questions & 325.50 & -1.699 & 0.089 & $C G I=S G I$ & 245.00 & -3.366 & $0.001^{*}$ & CG $\|>S G\|$ \\
\hline \multirow{7}{*}{ 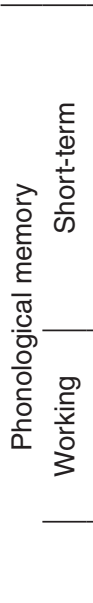 } & $\begin{array}{l}\text { DS sequential order } \\
\text { (length) }\end{array}$ & 358.00 & -1.041 & 0.298 & CG I=SG I & 164.00 & -4.378 & $0.000^{*}$ & CG $\|>S G\|$ \\
\hline & $\begin{array}{l}\text { DS sequential order } \\
\text { (score) }\end{array}$ & 375.00 & -0.724 & 0.469 & CG I=SG I & 191.50 & -3.817 & $0.000^{\star}$ & CG $\|>S G\|$ \\
\hline & $\begin{array}{l}\text { Repetition of pseudowords } \\
\text { (length) }\end{array}$ & 218.50 & -3.507 & $0.000^{*}$ & CG I>SG I & 235.00 & -4.203 & $0.000^{*}$ & CG $\|>S G\|$ \\
\hline & $\begin{array}{l}\text { Repetition of pseudowords } \\
\text { (score) }\end{array}$ & 232.00 & -2.866 & $0.004^{*}$ & CG I>SG I & 225.50 & -3.328 & $0.001^{*}$ & CG $\|>S G\|$ \\
\hline & $\begin{array}{l}\text { DS backward order } \\
\text { (length) }\end{array}$ & 235.00 & -3.156 & $0.002^{*}$ & CG I>SG I & 153.00 & -4.596 & $0.000^{\star}$ & CG $\|>S G\|$ \\
\hline & DS backward order (score) & 208.00 & -3.344 & $0.001^{*}$ & CG I>SG I & 186.50 & -3.905 & $0.000^{*}$ & $C G\|>S G\|$ \\
\hline & DS weighted score & 249.00 & -2.602 & $0.009^{*}$ & CG I>SG I & 161.00 & -4.209 & $0.000^{*}$ & CG $\|>S G\|$ \\
\hline 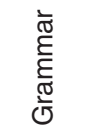 & Grammatical closure & 123.00 & -4.498 & $0.000^{*}$ & CG I>SG I & 163.50 & -4.189 & $0.000^{*}$ & CG $\|>S G\|$ \\
\hline \multirow{4}{*}{ 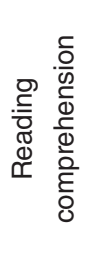 } & Total score & 50.50 & -5.569 & $0.000^{*}$ & CG I>SG I & 15.00 & -6.300 & $0.000^{*}$ & $C G\|>S G\|$ \\
\hline & Literal questions & 56.00 & -5.556 & $0.000^{*}$ & CG I>SG I & 162.00 & -4.701 & ${ }^{\prime} 0.000^{*}$ & CG $\|>S G\|$ \\
\hline & Text-connecting questions & 125.00 & -4.455 & $0.000^{*}$ & CG I>SG I & 81.00 & -5.388 & $0.000^{\star}$ & $C G\|>S G\|$ \\
\hline & Gap-filling questions & 121.50 & -4.505 & $0.000^{*}$ & CG I>SG I & 58.00 & -5.713 & $0.000^{\star}$ & $C G\|>S G\|$ \\
\hline
\end{tabular}

*Statistically significant values ( $p \leq 0.01)$ : Mann-Whitney's test; **statistically significant values $(p \leq 0.05)$

Caption: CG I = control group in Cycle I; SG I = study group in Cycle I; CG II = control group in Cycle II; SG I = study group in Cycle II; Z = Z-score; DS = digit span

Upon comparing the reading comprehension performances in the SGs, we observed similar performances concerning all variables studied. Following the comparison of the performances on tasks that addressed underlying abilities, the students in CG II showed better performances than those in CG I, except in tasks of text decoding and oral comprehension, weighted score of digit span. The comparison between the SGs showed similar performances on the tests of text decoding, oral comprehension, short-term phonological memory (digits and pseudowords), and reading comprehension. Concerning the other tasks (word decoding and isolated pseudowords, working phonological memory, and grammar closure), SG II showed better performances than SG I. 
Table 3. Intercycle comparison

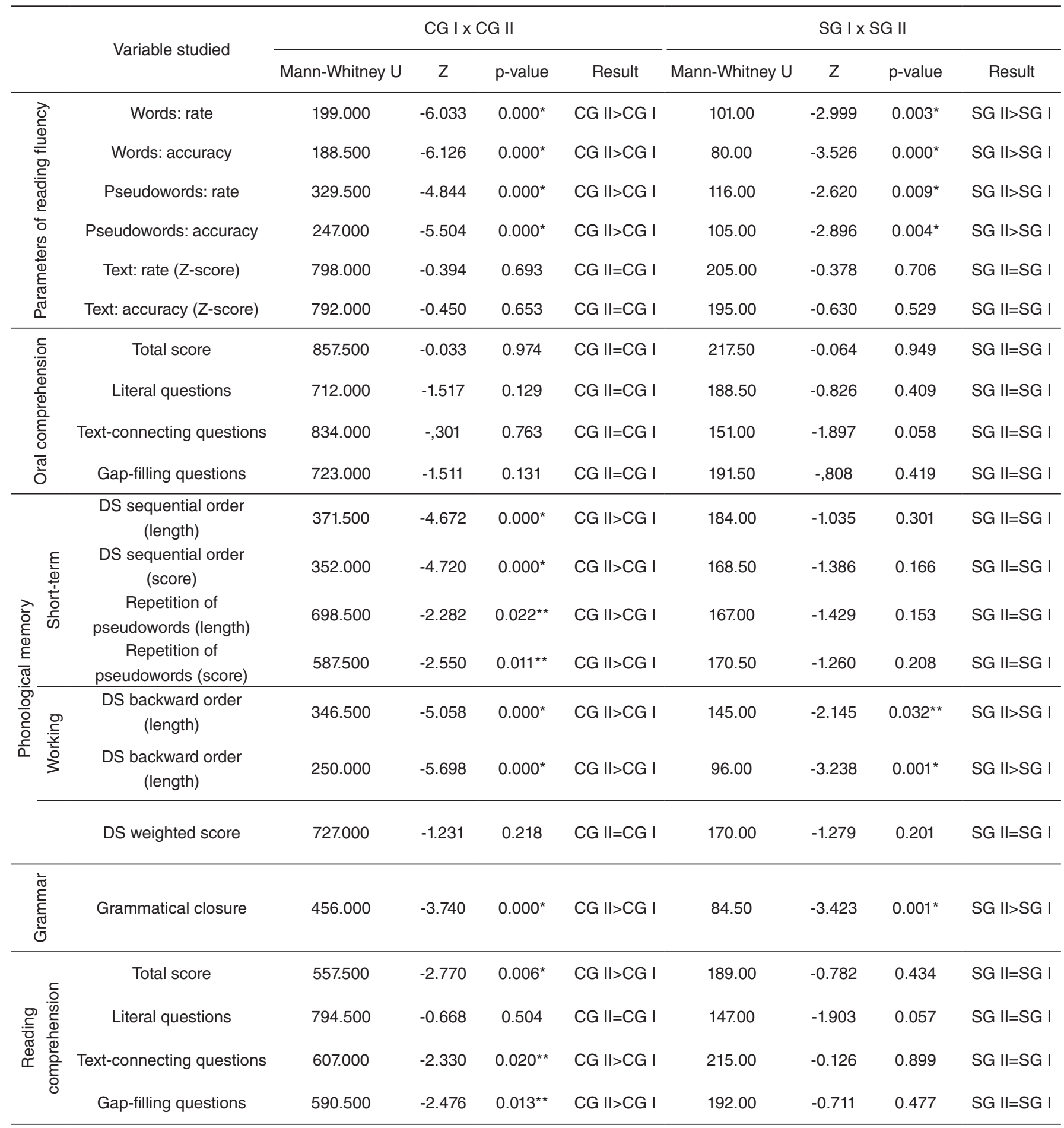

*Statistically significant values ( $\leq \leq 0.01)$ : Mann-Whitney's test; ** statistically significant values $(p \leq 0.05)$

Caption: CG I = control group in Cycle I; SG I = study group in Cycle I; CG II = control group in Cycle II; SG I = study group in Cycle II; Z = Z-score; DS = digit span

In CG I, the results of the correlation between the variables of reading comprehension and the other variables in the study were positive between the total reading comprehension score and variables of reading fluency of words (rater $=0.471$ and $p=0.02$; accuracy: $r=0.5$ and $p=0.001$ ), pseudowords (rate: $r=0.516$ and $\mathrm{p}=0.00$; accuracy: $\mathrm{r}=0.496$ and $\mathrm{p}=0.001$ ), and text (rate: $\mathrm{r}=0.563$ and $\mathrm{p}=0.00$; accuracy: $\mathrm{r}=0.583$ and $\mathrm{p}=0.00$ ); between
LIT questions and parameters of reading fluency of texts (rate: $\mathrm{r}=0.379$ and $\mathrm{p}=0.029$; accuracy: $\mathrm{r}=0.381$ and $\mathrm{p}=0.014$ ); between TC questions and parameters of reading fluency of words (rate: $\mathrm{r}=0.457$ and $\mathrm{p}=0.002$; accuracy: $\mathrm{r}=0.463$ and $\mathrm{p}=0.002$ ), pseudowords (rate: $\mathrm{r}=0.388$ and $\mathrm{p}=0.011$ ), and text (rate: $\mathrm{r}=0.451$ and $\mathrm{p}=0.003$; accuracy: $\mathrm{r}=0.452$ and $\mathrm{p}=0.003$ ); between GF questions and variables of reading comprehension and parameters 
of reading fluency of pseudowords (rate: $\mathrm{r}=0.374$ and $\mathrm{p}=0.015$; accuracy: $r=0.427$ and $p=0.005$ ) and text (rate: $r=0.331$ and $\mathrm{p}=0.035$; accuracy: $\mathrm{r}=0.360$ and $\mathrm{p}=0.021$ ).

In SG I, we observed correlations between the total reading comprehension score and the variables reading rate of words $(\mathrm{r}=-0.447$ and $\mathrm{p}=0.048)$ and grammatical closure $(\mathrm{r}=0.551$ and $\mathrm{p}=0.012$ ); between LIT questions of reading comprehension and the variables accuracy of pseudowords $(r=-0.456$ and $\mathrm{p}=0.043$ ) and working phonological memory performance (sequence length: $\mathrm{r}=0.521$ and $\mathrm{p}=0.018$; score: $\mathrm{r}=0.589$ and $\mathrm{p}=0.0006$ ); and between GF questions and grammatical closure $(\mathrm{r}=0.600$ and $\mathrm{p}=0.005)$.

In CG II, we found the following correlations pertaining to cycle II: between the total reading comprehension score and length of repetition of digits in sequential order $(r=0.432$ and $\mathrm{p}=0.005$ ); between LIT questions and scores of repetition of pseudowords ( $\mathrm{r}=0.449$ and $\mathrm{p}=0.03$ ); between $\mathrm{GF}$ questions and the variables total oral comprehension score $(r=0.326$ and $\mathrm{p}=0.038$ ) and repetition of digits in sequential order (sequence length: $r=0.425$ and $p=0.006$; score: 0.378 and $p=0.05$ ).

In SG II, the analysis of the correlation between the variables of reading comprehension and other variables that underlie reading showed a correlation between TC questions and accurate reading of pseudowords $(\mathrm{r}=0.429$ and $\mathrm{p}=0.046)$.

Upon comparing the older students (SG II, Cycle II) who have poor reading comprehension than the younger students (CG I, Cycle I), we found that students of CG I performed better on all reading comprehension tasks. Furthermore, both groups had similar results on tasks of decoding in regard to reading isolated items, short-term phonological and working memory (digits), and grammatical closure (Table 4). Concerning the other tasks and variables (reading fluency of texts, oral comprehension, and repetition of pseudowords), students of CG I showed better performances than those of SG II.

\section{DISCUSSION}

In this study, we investigated reading comprehension and its underlying abilities and aimed at characterizing and comparing them at the end of both cycles of ES. Several oral language skills are the foundation for the construction of reading comprehension ability ${ }^{(3-5,7-9,30)}$, and, not rarely, clinical cases in Speech-Language Pathology and Audiology evidence manifestations of language deficits and impaired information processing associated with reading and writing disorders. Reading comprehension develops concomitantly with the progress of cognitive and language functions and abilities that will support it, such as, oral comprehension, short-term and working memory, and syntactic competence, in addition to decoding the writing system $^{(1,2,6,7,10-17,23,24,30)}$. The concern with acquiring literacy in the first years of school is justifiable. However, according to the NCP, already at the end of Cycle I of ES students are expected, through the gradual accumulation of experience, to be able to extract meaning when linking the texts read to their context. In addition, they are expected to be able to use cognitive tools to elaborate and confirm anticipations, deductions, and inferences about the content read so as to clarify any doubts concerning what was read and thus learnt ${ }^{(19)}$. Therefore, in Cycle I, the students must master from the alphabetic principle to some level of reading comprehension.

In respect to these curricular expectations, it was possible to observe, by analyzing Cycle I, that the students indicated by their teachers as having good reading comprehension (CG I) showed adequate performances on the tests used to assess reading fluency (Table 1) and better reading comprehension performances in comparison to those indicated as having poor reading comprehension (SG I). Authors in some studies $^{(11,23,30)}$ recognize the importance of reading fluency for textual comprehension, especially in early school grades, and emphasize the possibility of a reader redirecting his/her attention toward the comprehension of a text when decoding is performed effortlessly, which can explain, even if partially, the better performances in CG I on the tasks of reading comprehension. The analysis of the correlations investigated in CG I corroborates these results. Moreover, with exception of the answers given to GF questions concerning oral comprehension and short-term memory, the younger students with good reading comprehension also showed better performances than their counterparts with poor reading comprehension on the other tasks that addressed abilities related to reading comprehension competence, reported in the literature and studied here ${ }^{(4,6,17,18,23,24)}$.

Considering the NCP's guidelines ${ }^{(19)}$ and the results presented by CG I as reference points for discussion, we must highlight that, although the students in SG I read the texts and achieved some level of comprehension, repeated digits and words in sequential and backward order, and answered questions of grammatical closure and oral comprehension, they were slower and less precise when reading texts and isolated items, less competent to meet syntactic and semantic demands during oral evaluations, and less capable to memorize increasingly longer sequences of linguistic stimuli in comparison to their counterparts who had good comprehension. These students with poor reading comprehension showed performances similar to CG I only on the tasks that required the repetition of a sequence of digits and addressed comprehension through GF. In other words, the abilities involved in short-term memory and in processing experiential knowledge during activities of deductive reasoning, proper to this age range, were adequate even when reading comprehension was poor. The correlations found upon analyzing SG I allow us to raise the hypothesis that the students in this group, with poorer reading comprehension performances, may have made little use of their capability to decode with the purpose of comprehending the text, as the variables accuracy of pseudowords, rate of word reading, and reading comprehension (LIT questions and total score, respectively, to the variable reading fluency) increased in opposite directions.

In addition to this, the correlations in this group showed a moderate positive association between working memory along with correct answers given to LIT questions and the total reading comprehension score. In other words, it is possible to consider the hypothesis that the students in SG I were able to use memory resources to achieve reading comprehension. The individuals in SG I also showed that they were able to use resources 
Table 4. Comparison between control group I and study group II

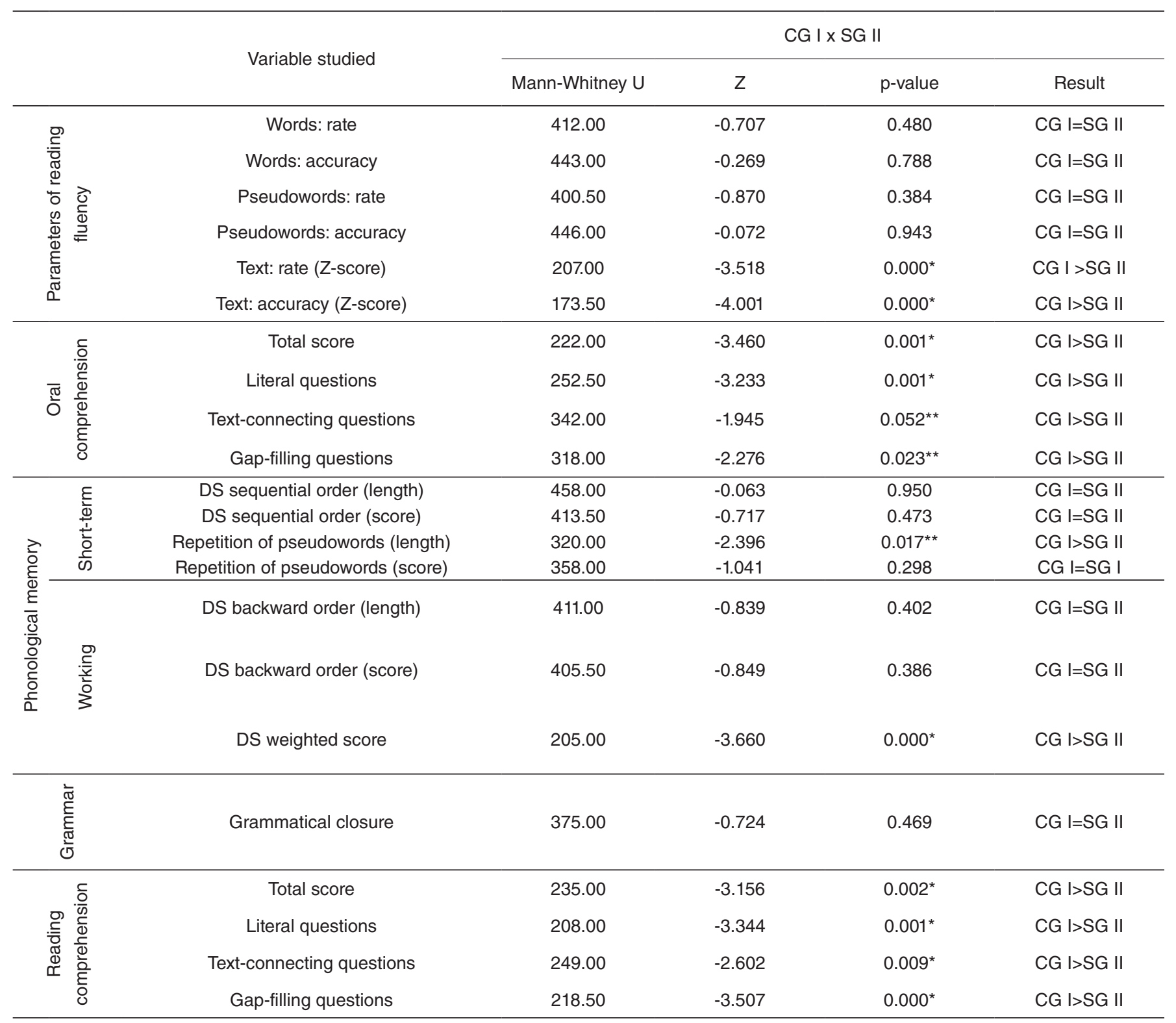

*Statistically significant values $(p \leq 0.01)$ : Mann-Whitney's test; **statistically significant values $(p \leq 0.05)$

Caption: CG I = control group in Cycle I; SG II = study group in Cycle II; Z = Z-score; DS = digit span

related to grammatical competence and working memory to answer the GF questions.

At the end of Cycle II, during the phase of formal reasoning, students must be able to achieve more abstract and profound levels of reading comprehension, as active and critical readers, when constructing a mental image of the text read and repairing this image whenever necessary ${ }^{(3)}$.

The analysis of the correlations allows us to raise the hypothesis that the students indicated by their teachers as having good reading comprehension, in Cycle II of ES, used their resources of short-term memory to achieve better textual comprehension performances. Despite the possibility of achieving more abstract levels of reasoning and cognitive processing, the results found for the students in SG II showed poorer performances on all tasks of reading comprehension as well as on the other tests used to evaluate reading fluency, oral comprehension, phonological memory, and grammatical competence in comparison to CG II. The analysis of the correlations in SG II showed that only the accurate reading of pseudowords was associated with reading comprehension efforts, especially on the tasks that involved TC inferences.

It is possible to think, then, that a composition of different characteristics was found upon comparing the groups with older students, because skills of oral comprehension linked to GF and of short-term phonological memory, similar among younger students, proved to be different at the end of Cycle II. In other words, the similarities found at the end of Cycle I were not evidenced in Cycle II. The possibility that reading contributes to the development of oral language is suggested here ${ }^{(14,15)}$, as the GF inferences used in oral comprehension, adequate in 
SG I, were not properly accessed by the students in SG II to comprehend the story they heard.

The comparison of the reading comprehension displayed by both CGs, in both stages of ES, showed, as expected, similar performances concerning the answers given to LIT questions ${ }^{(15,24)}$ and better performances achieved by the older students when answering questions that required the construction of inferences through deeper deductive reasoning and working memory $^{(10,13,28)}$. When compared in regard to grammatical closure, CG II showed better performances. On the other hand, the students' oral comprehension was similar, probably due to the characteristics of the instrument used. The better results observed in CG II in relation to CG I also seem to reinforce the idea that the more fluent the reading, the better the comprehension ${ }^{(30)}$, as reading comprehension was better in CG II as well. These results suggest that students considered as having good reading comprehension indeed improve their abilities over the course of schooling and their development.

Contrary to what was found in the analysis of the CGs, the comparison between the SGs showed similar performances in both stages of ES on all tasks used to evaluate reading comprehension, which was not expected. And, considering the low scores of answers of both groups, it is possible to affirm that the better performances on reading fluency of isolated items shown by SG II did not contribute to the development of reading comprehension. Moreover, the comparative analysis did not show any differences either in rate and accuracy during text reading (Z-scores) or in the tasks that evaluated oral comprehension and short-term phonological memory. However, by studying the underlying abilities, we found that the older students in the SG presented better performances concerning phonological working memory and grammatical competence, as well as better reading fluency, as mentioned previously.

Our comparisons showed that there were more similarities related to reading comprehension when we comparatively observed the younger and older students in the SG than when we compared the students with good comprehension among themselves. Considering that all students are enrolled in the same school system, with similar socioeconomic levels and in the same geographical region, it is possible to think that the schools, unprepared to deal with students who have functional deficits, do not promote the development of reading comprehension and the abilities related to it. However, as it occurred in the comparison between the CGs, the comparison between the SGs suggests that, even in the presence of impaired reading comprehension, phonological working memory and grammatical closure developed themselves as age progressed, regardless of the development of other abilities that concur for adequate reading comprehension. The same was observed in regard to reading fluency parameters, which presented higher values in SG II.

On the basis of the affirmation that older students with poor comprehension can be similar to younger students without impairments or indicators of reading alterations and deficits in some parameters ${ }^{(24)}$, we proceeded to compare the performances in SG II to those in CG I. We found that SG II had poorer performances on the tasks that evaluated reading comprehension.
This result evidences that the older students were not able to reach even the level of reading comprehension prescribed by the $\mathrm{NCP}^{(19)}$ for students in Cycle I. We observed lower values of rate and accuracy in the task of oral textual reading, despite the similar values obtained on the task of reading isolated items. Probably, the resources available from high-order cognitive mechanisms involved in reading comprehension could not be activated, contrary to what occurred in the case of the younger readers with good reading comprehension, who sped up reading by appropriating the meaning of what was read.

Although working and short-term phonological memory as well as grammatical knowledge of students in SG II were better than those in SG I, which suggests that the development of these abilities unfolded as age progressed, the values were low in comparison to those observed in SG II. Aggravating the difficulty to memorize and operate with textual propositions, we observed reading comprehension impairments related to inferential and other processes involved in reading comprehension in SG II ${ }^{(30)}$. However, in comparison to CG II, we must consider that the texts used to evaluate the students in SG II were adequate to their age range but not to their ability to decode, which was below the expected on the tasks that assessed reading fluency. Therefore, the cognitive demands that surpassed their ability to decode may have influenced the lower results found during the evaluation of reading comprehension in SG II. The comparison of these reading comprehension results, using the same texts used for CG I and SG II, can perhaps show better performances in the older group of poor comprehenders on this test.

The fact that this was not a longitudinal study limits the considerations to be weaved about the development of the underlying abilities found in students of Cycle I and no longer observed when comparing more advanced ages and stages in the SG. The several comparisons carried out showed that the students in Cycle I, with or without good reading comprehension, presented similar capacity for memory and oral language that must be recognized and stimulated naturally, even when their performances, appreciated through their reading skills, are below the expectations. The students in the last grades of Cycle II of ES, with poor reading comprehension, showed some level of development pertaining to memory and language skills - because their performances were better than those in SG I - but not to their full extent. However, their development was below the expected in comparison to the younger students with good reading comprehension. The correlations found showed that these students, albeit with a lesser competence, use resources from cognitive skills during the act of reading to achieve comprehension. For this reason, they must be stimulated.

Overall, the results show that schooling indeed promotes the development of some underlying abilities that are not, however, sufficient to ensure that the students will achieve reading comprehension. They also suggest that these individuals have deficits that underlie those manifested as reading skills, which the school structure is not yet prepared to address, in the sense of fulfilling the needs of students who have some abilities that can and must be developed beyond what is manifested. 


\section{CONCLUSION}

The analyses conducted to characterize the students' performances, with and without reading comprehension impairments, on tasks that addressed comprehension and abilities that underlie reading, allow us to conclude that the students considered as having good reading comprehension showed better reading fluency, reading comprehension, and grammatical closure performances than those with poor reading comprehension, regardless of the ES cycle. Despite this difference, the abilities involved in working memory and oral comprehension did not differentiate students with good and poor reading comprehension in Cycle I, contrary to what we observed in Cycle II. Generally, the students with poor reading comprehension in Cycle II presented similar or better performances than those in Cycle I who had the same level of comprehension, and similar or worse performances than those in Cycle I who had good reading comprehension. Finally, the investigation of the correlations between the abilities that underlie reading in the four groups evaluated showed that these skills were associated with reading comprehension according to the different profiles of each group of students. Thus, they corroborated the results concerning better or poorer performances found upon comparing the groups.

\section{ACKNOWLEDGMENT}

We acknowledge the financial support provided by the Conselho Nacional de Desenvolvimento Científico e Tecnológico (CNPq) for this study (process number 133731/2011-1).

*EMC was in charge of data collection, tabulation and analysis; CRBA was responsible for the study Project and design, and for the general orientation of the stages of execution and elaboration of the manuscript

\section{REFERENCES}

1. Oakhill JV, Cain K. The precursors of reading ability in young readers: evidence form a four-year longitudinal study. Scientific Studies of Reading. 2012;16(2):91-121.

2. Duff FJ, Hulme C. The role of children's phonological and semantic knowledge in learning to read words. Scientific Studies of Reading. 2012;16(6):504-25.

3. Olson RK, Keenan JM, Byrne B, Samuelsson S. Why Do Children Differ in Their Development of Reading and Related Skills? Scientific Studies of Reading. 2013;18(1):38-54.

4. Catts HW, Adlof SM, Weismer SE. Language deficits in poor comprehenders: a case for the simple view of reading. J Speech Lang Hear Res. 2006:49:278-93.

5. Cain K, Oakhill J. Profiles of children with specific reading comprehension difficulties. Br J Educ Psychol. 2006;76:683-96.

6. Nascimento TA, Carvalho CAF, Kida ASB, Avila CRB. Fluência e compreensão leitora em escolares com dificuldades de leitura. Rev Soc Bras Fonoaudiol. 2011;23(4):335-43.

7. Avila CRB, Carvalho CAF, Kida ASB. Parâmetros de fluência e compreensão de leitura. In: Barbosa T, Rodrigues CC, De Mello CB,
Capellini SA, Mousinho R, Alves LM, organizadores. Temas em dislexia. São Paulo: Artes Médicas; 2009. p. 36-60.

8. Oakhill JV, Cain K, Bryant PE. The dissociation of word reading and text comprehension: evidence from component skills. Language and Cognitive Processes. 2003;18(4):443-68.

9. Pennington BF, Bishop DVM. Relations among speech, language, and reading disorders. Annu Rev Psychol. 2009;60:283-306.

10. Oakhill JV. Inferential and memory skills in children's comprehension of stories. Br J Educ Psychol. 1984;54:31-9.

11. Cunha VLO, Capellini SA. Desempenho de escolares de $1^{\mathrm{a}}$ a $4^{\mathrm{a}}$ série do ensino fundamental nas provas de habilidades metafonológicas e de leitura - PROHMELE. Rev Soc Bras Fonoaudiol. 2009;14(1):56-68.

12. Tong X, Dacon SH, Kirby JR, Cain K, Parrila P. Morphological awareness: a key to understanding poor reading comprehension in English. Journal of Educational Psychology. 2011;103(3):523-34.

13. Vellutino FR, Tunmer WE, Jaccard JJ, Chen R. Components of reading ability: multivariate evidence for a convergent skills model of reading development. Scientific Studies of Reading. 2007;11(1):3-32.

14. Cain K, Oakhill JV, Bryant PE. Investigating the causes of reading comprehension failure: the comprehension-age match design. Reading and Writing. 2000;12(1-2):31-40

15. Cain K, Oakhill JV, Barnes MA, Bryant PE. Comprehension skill, inference making ability and their relation to knowledge. Mem Cognit. 2001;29(6):850-9.

16. Giangiacomo MCPB, Navas ALGP. A influência da memória operacional nas habilidades de compreensão de leitura em escolares de $4^{\mathrm{a}}$ série. Rev Soc Bras Fonoaudiol. 2008;13(1):69-74.

17. Oliveira AM, Cardoso MH, Capellini AS. Caracterização dos processos de leitura em escolares com dislexia e distúrbio de aprendizagem. Rev Soc Bras Fonoaudiol. 2012;17(2):201-7.

18. Florit E, Roch M, Levorato C. Listening text comprehension of explicit and implicit information in preschoolers: the role of verbal and inferential skills. Discourse Processes. 2011;48:119-38.

19. Brasil. Ministério da Educação. Parâmetros Curriculares Nacionais: terceiro e quarto ciclos de ensino fundamental: língua portuguesa/ Secretaria de Educação Fundamental. Brasília: MEC/SEF; 1998.

20. Kruk RS, Bergman K. The reciprocal relations between morphological processes and reading. J Exp Child Psychol. 2013;114(1):10-34.

21. Snowling MJ, Stothard SE, Clarke P, Bowyer-Crane C, Harrington A, Truelove E. York assessment of reading for comprehension. Nova York: GL Assessment; 2009.

22. Instituto Nacional de Estudos e Pesquisas Educacionais Anísio Teixeira [Internet]. Data Escola Brasil. [citado 28 Maio 2014] Disponível em: http://www.dataescolabrasil.inep.gov.br/dataEscolaBrasil/

23. Carvalho CAF, Avila CRB, Chiari BM. Níveis de compreensão de leitura em escolares. Pró-Fono R Atual Cient. 2009:21(3):207-12.

24. Cain K, Oakhill JV. Inference making and its relation to comprehension failure. Reading and Writing. 1999;11:489-503.

25. Bueno GJ. Instrumentos de avaliação da compreensão leitora: análise da propriedade do texto narrativo e das questões de inferência [trabalho de conclusão de curso]. São Paulo: Universidade Federal de São Paulo; 2012.

26. Lobato M. Histórias da tia Nastácia. $32^{a}$ edição. São Paulo: Brasiliense; 2002. p. 81-2.

27. Wechsler D. Wechsler Intelligence Scale for Children - Third edition (WISC-III): manual. San Antonio: Psychological Corporation; 1991.

28. Figueiredo VLM, Nascimento E. Desempenhos nas duas tarefas do subteste dígitos do WISC-III e do WAIS-III. Psicol Teor Pesqui. 2007;23(3):313-8.

29. Bogossian MADS. Teste de Illinois de habilidades psicolinguísticas: crítica do modelo mediacional e de diversos aspectos da validade do instrumento [tese]. Rio de Janeiro: Fundação Getulio Vargas; 1984.

30. Hulme C, Snowling MJ. The interface between spoken and written language: developmental disorders. Phil Trans R Soc B. 2014;369:1-9. 